\title{
Hava Durumu Anomalisi: Panel Veri Analizi
}

Aysel GÜNDOĞDU ${ }^{1}$ - Selin SARILI ${ }^{2}$

Makale Gönderim Tarihi: 22 Temmuz 2021

Makale Kabul Tarihi: 15 Eylül 2021

\section{$\ddot{O} z$}

Finansal piyasalarda işlem yapan yatırımcıların her ne kadar rasyonel oldukları varsayılsa da her zaman bu koşulun geçerli olmadığı davranışsal finans teorisinde yer alan anomalilerle açıklanmaya çalışılmaktadır. Finansal piyasa anomalilerinden biri olan hava durumu anomalisi de, hava koşullarının bireylerin psikolojisi üzerinde ve dolayısı ile yatırım kararlarında etkili olduğunu öne sürmektedir. Çalışmada davranışsal finans teorisinde yer alan 'hava durumu anomalisi' nin test edilmesi amaciyla 6 ülkeye (Türkiye, İtalya, Amerika Birleşik Devletleri, Kanada, Çin, Rusya) ait hava durumu ve ülkelerin ana borsa endeksleriyle (Bist100, FTSE MIB, Dow Jones Industrial Average, S\&P_TSX, Shanghai Composite, MOEX Russia) panel veri analizi yapılmıştır. Çalışmaya 04.01.2010 ile 31.07.2019 tarih aralığında günlük veriler dahil edilmiştir. Öncelikle panel birim kök testleriyle serilerin durağanlıkları araştırılmış, sonrasında ise panel eşbütünleşme testleri uygulanmıştır. Johansen eşbütünleşme testi sonucunda sadece Rusya ve Kanada için eşbütünleşme ilişkisi bulunmuştur.

Anahtar Kelimeler: Hava durumu anomalisi, panel veri, eşbütünleşme.

JEL Sınıflandırması: G12, G15, C23

1 Doç. Dr., İstanbul Medipol Üniversitesi, e-mail: ayselerbas@gmail.com, Orcid: 0000-0002-49184598, Tel: 05319928040.

2 Dr. Öğr. Üyesi, İstanbul Şişli Meslek Yüksekokulu, e-mail: selin.sarili@sisli.edu.tr, Orcid: 00000003-4481-6215, Tel: 05337282856. 


\title{
Weather Anomaly: Panel Data Analysis
}

\begin{abstract}
Although it is assumed that investors who are traded in financial markets are rational, it is tried to be explained by anomalies in behavioral finance theory that this condition does not always obtained. Weather anomaly, which is one of the financial market anomalies, suggests that weather conditions have an effect on the psychology of individuals and thus on investment decisions. In this study, panel data analysis was carried out by using the weather data of 6 countries (Turkey, Italy, the United States, Canada, China, Russia) and the main stock indexes (Bist100, FTSE MIB, Dow Jones Industrial Average, S\&P_TSX, Shanghai Composite, MOEX Russia) of the countries in order to test the weather anomaly located in the behavioral finance theory. Daily data were included in the study between 04.01.2010 and 31.07.2019. First of all, the stability of the series was investigated with panel unit root tests and then panel co-integration tests were applied. As a result of Johansen cointegration test, cointegration relationship was found only for Russia and Canada.
\end{abstract}

Keywords: Weather anomaly, panel data, co-integration.

JEL Classification: G12, G15, C23

\section{Giriş}

Psikoloji biliminde insanların psikolojik durumları ile hava durumu arasında bir ilişki olduğu çeşitli çalışmalarda ortaya konmuştur. Bu çalışmalara göre hava güneşli ise insanlar daha iyimser ve mutlu, hava yağmurlu ve kapalı ise daha kötümser ve mutsuz olabilirler. Bu ilişki davranışsal finansta yatırımcıların getirileri ile işlem yapılan günlerdeki hava durumu arasında bir ilişki olup olmadığı sorusunu ortaya çıkarmıştır. Bu soruya yanıt arayan ilk çalışmada Saunder (1997) New York Borsası'nda işlem gören hisse fiyatları ile hava durumu arasındaki ilişkiyi test etmiştir. Çalışmanın sonucuna göre hisse fiyatları ile hava durumu arasında pozitif bir ilişki vardır. Buna karşın Trombley (1997) çalışmasında yine New York Borsası'nda işlem gören hisse fiyatları ile hava durumu arasındaki ilişkiyi test etmiştir. Bu çalışmada ise herhangi bir anlamlı ilişkiye rastlanmamıştır. Tablo 1'de hava durumu ve borsa getirileri arasındaki ilişkiyi ölçen ampirik çalışmaların listesine yer verilmiştir. Görüldügü üzere, çalışmaların bazılarında ilişki var, bazılarında yok çıkmıştır. Bu nedenle literatürde belirli bir sonuca ulaşıldığını söylemek mümkün değildir. 


\section{Tablo 1. Hava Durumu ve Borsa Getirileri Arasindaki İlişkiyi Ölçen Ampirik Çalışmalar}

\begin{tabular}{|c|c|c|c|}
\hline Yazar(lar) & Kapsam & Yöntem & Sonuçlar \\
\hline Hirshleifer ve Shumway (2004) & Sabah güneşinin borsa yatırımları ile ilişkisi & $\begin{array}{l}\text { Regresyon ve Logit } \\
\text { Model }\end{array}$ & İlişki var \\
\hline Saunders (1993) & $\begin{array}{l}\text { New York'ta hava koşullarının hisse fiyatları } \\
\text { üzerindeki etkisi }\end{array}$ & Regresyon & iliş̧ki var \\
\hline Dowling ve Lucey (2005) & $\begin{array}{l}\text { İrlanda'da hisse fiyatları ile hava durumu } \\
\text { arasındaki ilişki }\end{array}$ & Regresyon & ilişki var \\
\hline Symeonidis vd. (2009) & $\begin{array}{l}\text { Hisse piyasasının dalgalanması ile hava duru- } \\
\text { mu arasındaki ilişki }\end{array}$ & Regresyon & ilişki var \\
\hline Cao ve Wei (2005) & $\begin{array}{l}\text { Hava durumunun hisse piyasasını etkileyip } \\
\text { etkilemediğini test etme }\end{array}$ & Regresyon & ilişki var \\
\hline Chang vd. (2006) & $\begin{array}{l}\text { Tayvan'da hava durumu ile borsa arasındaki } \\
\text { ilişkisi }\end{array}$ & GJR-GARCH & ilişki var \\
\hline $\begin{array}{l}\text { Gunasekara ve Jayasinghe } \\
\text { (2019) }\end{array}$ & $\begin{array}{l}\text { Hava durumunun hisse piyasasını etkileyip } \\
\text { etkilemediğini test etme }\end{array}$ & VAR - Vector & ilişki var \\
\hline Sariannidis vd. (2015) & $\begin{array}{l}\text { Hava durumunun hisse piyasasını etkileyip } \\
\text { etkilemediğini test etme }\end{array}$ & Autogressive model & ilişki var \\
\hline Trombley (1997) & $\begin{array}{l}\text { New York’ta hava durumu ile borsa arasın- } \\
\text { daki ilişkisi }\end{array}$ & Regresyon & İlişki yok \\
\hline Cullen (2003) & $\begin{array}{l}\text { New York’ta hava koşullarının piyasa hacmi } \\
\text { üzerindeki etkisi }\end{array}$ & $\begin{array}{l}\text { Korelasyon ve reg- } \\
\text { resyon }\end{array}$ & İlişki yok \\
\hline $\operatorname{Kim}(2016)$ & $\begin{array}{l}\text { Hisse getirileri ile hava durumu arasındaki } \\
\text { ilişki }\end{array}$ & Regresyon & ilişki yok \\
\hline Pardo ve Valor (2003) & $\begin{array}{l}\text { İspanya'da hava durumu ile borsa arasındaki } \\
\text { ilişsisi }\end{array}$ & Regresyon & ilişki yok \\
\hline Goetzmann ve Zhu (2003) & $\begin{array}{l}\text { Hava durumu ile yatırımcının işlemleri ara- } \\
\text { sındaki ilişki }\end{array}$ & Regresyon & ilişki yok \\
\hline Wang vd. (2018) & $\begin{array}{l}\text { Hava durumunun hisse piyasasını etkileyip } \\
\text { etkilemediğini test etme }\end{array}$ & Regresyon & ilişki yok \\
\hline Kang vd. & $\begin{array}{l}\text { Hong-Kong’ta hisse getirileri ile hava durumu } \\
\text { arasındaki ilişki }\end{array}$ & Regresyon & ilişki yok \\
\hline Tufan ve Hamarat (2004) & $\begin{array}{l}\text { IMKB } 100 \text { endeksinde hava durumunun } \\
\text { etkisini araştırmak }\end{array}$ & Unit Root Test. & ilişki yok \\
\hline Kamstra (2003) & $\begin{array}{l}\text { ABD, İsveç, İngiltere, Almanya, Kanada, } \\
\text { Yeni Zelanda, Japonya, Avustralya ve Güney } \\
\text { Afrika ülkelerinin hava durumu ile hisse } \\
\text { piyasaları ilişkisi }\end{array}$ & $\begin{array}{l}\text { Korelasyon ve reg- } \\
\text { resyon }\end{array}$ & $\begin{array}{l}\text { Kuzeydeki } \\
\text { ülkelerde } \\
\text { etki daha } \\
\text { yüksek }\end{array}$ \\
\hline Loughran (2003) & $\begin{array}{l}\text { Bulutlu havaların şirket getirileri üzerindeki } \\
\text { etkisi }\end{array}$ & $\begin{array}{l}\text { Regresyon ve Logit } \\
\text { Model }\end{array}$ & Sınırlı etki \\
\hline Zeren ve Gümüş (2015) & $\begin{array}{l}\text { Türkiye, Fransa, Belçika ve Yunanistan'da } \\
\text { günlük sıcaklıkların borsaya olan etkisini } \\
\text { araştırmak }\end{array}$ & $\begin{array}{l}\text { Bootstrap nedensellik } \\
\text { testi }\end{array}$ & Sinırlı Etki \\
\hline
\end{tabular}

\section{Metodoloji ve Veriler}

Çalışmada davranışsal finans teorisinde yer alan "hava durumu anomalisi"nin test edilmesi amacıyla, 6 ülkede borsaların bulunduğu şehirlere (Türkiye-İstanbul, İtalya-Milano, Amerika Birleşik Devletleri-New York, Kanada-Toronto, Çin-Şangay, Rusya-Moskova) ait hava durumu ve ülkelerin ana borsa endeksleriyle (Bist100, FTSE MIB, Dow Jones Industrial Average, 
S\&P_TSX, Shanghai Composite, MOEX Russia) panel veri analizi yapılmıştır. Verilerle ilgili detaylı bilgi Ek.1'de verilmiştir. Çalışmaya 04.01.2010 ile 31.07.2019 tarih aralığında günlük veriler dahil edilmiştir. Borsa endekslerine ait veriler investing web sayfasından temin edilmiş ve günlük verilerle çalış1lmıştır. Eksik veri oluşmaması adına 6 ülke borsalarının, aynı anda açı olduğu günler çalışmaya dahil edilmiştir. Hava durumu verilerinde negatif değerlerin yer almasından dolayı logaritma alınmamış, orijinal serilerle çalışmaya devam edilmiştir.

\subsection{Panel Birim Kök Testleri}

Panel eşbütünleşme testlerinin ön koşulu olan panel birim kök testleri olarak Lin ve diğerleri(LLC), Im ve diğerleri(IPS), testleri,değişkenlerine sabit terim, trend ve sabit terimli olarak uygulanmıştır. LLC birim kök testi düzey halinde, "birim kök vardır" sıfır hipotezini taşımaktadır. Tablo 2'de ilk sütunda yer alan LLC testi düzey halinde reddedilememiştir. Tablo 2'nin yine ilk sütununda bulunan LLC testi, 1 . farkın alınmış olduğu koşulda yapılmaktadır ve "birim kök vardır" sıfir hipotezini reddederek, her iki değişkenin, sabit terimli, trendli ve sabit terimli durumlarında birim kök taşıdığını göstermektedir.

Bir diğer birim kök testi olan IPS testi de, LLC testi gibi "birim kök vardır" sıfır hipotezini taşımaktadır. IPS testi, LLC testi gibi birim kökün varlığını gösterecek şekilde sonuç vermiştir. Modelde bulunan değişkenlerin durağan olup olmadıkları panel birim kök testleri ile test edilmiştir. Test sonuçları Tablo 2'de yer almaktadır.

Tablo 2. Serilerin Düzey Değerlerine Ait Birim Kök Test Sonuçları

\begin{tabular}{|c|c|c|c|c|}
\hline & \multicolumn{2}{|c|}{ endeks ${ }_{i t}$} & \multicolumn{2}{|c|}{ havadurumu $_{i t}$} \\
\hline & Sabit & Sabit ve Trend & Sabit & Sabit ve Trend \\
\hline \multirow{2}{*}{ Metot } & \multicolumn{2}{|c|}{ Test İstatistiği } & \multicolumn{2}{|c|}{ Test İstatistiği } \\
\hline & \multicolumn{2}{|c|}{ Prob. } & \multicolumn{2}{|c|}{ Prob. } \\
\hline \multirow{2}{*}{ Levin, Lin \& Chu } & 1.22730 & 0.90155 & 1.19837 & 1.65068 \\
\hline & {$[0.8901]$} & {$[0.1836]$} & {$[0.8846]$} & {$[0.9506]$} \\
\hline \multirow{2}{*}{ Breitung $t$-stat } & & -2.51397 & & -2.15442 \\
\hline & & {$[0.0060]$} & & {$[0.0156]$} \\
\hline \multirow{2}{*}{$\begin{array}{l}\text { Im, Pesaran and Shin } \\
W \text {-stat }\end{array}$} & 0.47086 & 2.23641 & 6.05169 & 4.73892 \\
\hline & {$[0.6811]$} & {$[0.0127]$} & {$[0.0750]$} & {$[0.6282]$} \\
\hline \multirow{2}{*}{$A D F$ - Fisher Chi-square } & 11.0323 & 22.6841 & 66.9407 & 46.8911 \\
\hline & {$[0.5262]$} & {$[0.0305]$} & {$[0.0000]$} & {$[0.0000]$} \\
\hline \multirow{2}{*}{$P P$ - Fisher Chi-square } & 11.0351 & 21.6687 & 216.956 & 190.973 \\
\hline & {$[0.5259]$} & {$[0.0414]$} & {$[0.0000]$} & {$[0.0000]$} \\
\hline
\end{tabular}

*Parantez içindeki sonuçlar olasılık değerlerini ifade etmektedir. 
Endeks serisine ait birim kök sonuçlarına bakıldığında, sabitli modelde birim kök oldugu H0 hipotezi Levin, Lin ve Chu (LLC), Im, Pesaran ve Shin (IPS) $H_{0}$, Fischer-ADF ve Fischer-PP testlerine göre $\% 5$ anlamlıl1k düzeyinde reddedilememiş ve serilerin düzey değerlerinde durağan olmadıkları belirlenmiştir. Sabit ve trendli modelde ise yalnızca Breitung test sonucuna göre hipotezi reddedilerek, serinin durağan olduğu sonucu çıkmıştır.

Hava durumu serisine ait sonuçlara bakıldığında hem sabitli hem de sabit ve trendli model için Fischer-ADF ve Fischer-PP test sonuçlarına göre hipotezi $\% 5$ anlamlılık düzeyinde reddedilmiş ve serilerin düzey değerlerinde durağan oldukları belirlenmiştir.

Serilerin birim kök test sonuçlarının çelişkili olması ve ortak bir karara varılamaması nedeniyle, serilerin ilk farkları alınarak birim kök testleri yeniden uygulanmıştır. Serilere eşbütünleşme testi uygulayabilmek için, aynı mertebeden durağan olduklarının gösterilmesi gerekmektedir. Serilerin eşbütünleşik olduğunun tespit edilmesi halinde, serilerin düzey değerleriyle çalışmaya devam edilmesi mümkün olacaktır. Tablo 3 'te serilerin ilk farklarına ait panel birim kök sınama sonuçları yer almaktadır.

Tablo 3. Fark Serilerine Ait Birim Kök Test Sonuçları

\begin{tabular}{|c|c|c|c|c|}
\hline & \multicolumn{2}{|c|}{ endeks $_{i t}$} & \multicolumn{2}{|c|}{ havadurumu $_{i t}$} \\
\hline & Sabit & Sabit ve Trend & Sabit ve Trend & Sabit ve Trend \\
\hline \multirow{2}{*}{ Metot } & \multicolumn{2}{|c|}{ Test İstatistiğ $i$} & \multicolumn{2}{|c|}{ Test Istatistiği } \\
\hline & \multicolumn{2}{|c|}{ Prob. } & \multicolumn{2}{|c|}{ Prob. } \\
\hline \multirow{2}{*}{ Levin, Lin \& Chu } & 158.707 & 224.511 & 544.132 & 770.797 \\
\hline & {$[0.0000]$} & {$[0.0000]$} & {$[0.0000]$} & {$[0.0000]$} \\
\hline \multirow{2}{*}{ Breitung t-stat } & & -679.533 & & -465.168 \\
\hline & & {$[0.0000]$} & & {$[0.0000]$} \\
\hline \multirow{2}{*}{ Im, Pesaran and Shin $W$-stat } & 134.581 & 147.280 & 678.800 & 731.119 \\
\hline & {$[0.0000]$} & {$[0.0000]$} & {$[0.0000]$} & {$[0.0000]$} \\
\hline \multirow{2}{*}{ ADF - Fisher Chi-square } & 110.524 & 1580,34 & 1280,22 & 1580,34 \\
\hline & {$[0.0000]$} & {$[0.0000]$} & {$[0.0000]$} & {$[0.0000]$} \\
\hline \multirow{2}{*}{ PP - Fisher Chi-square } & 110.524 & 1580,34 & 110.524 & 647.593 \\
\hline & {$[0.0000]$} & {$[0.0000]$} & {$[0.0000]$} & {$[0.0000]$} \\
\hline
\end{tabular}

Tablo 3'te yer alan tüm test sonuçlarına bakıldığında hem ülkelere ait borsa verisinin, hem de hava durumu verisinin birinci mertebeden durağan oldukları görülmektedir. Her iki seri de I[1] olduğundan, serilerin düzey değerleriyle eşbütünleşme analizi yapmak mümkündür. 


\subsection{Eşbütünleşme Testi}

Değişkenlerin durağanlığını test etmek amacıyla panel birim kök testleri uygulanmış ve tüm değişkenlerin 1.mertebeden durağan olmaları sebebiyle eşbütünleşme testi yapılmıştır. Eşbütünleşmeyi test etmek amacıyla panel veriler için kullanılan Pedroni, Kao ve Fisher Johansen testleri uygulanmıştır.

Pedroni, panel verili modellerdeki eşbütünleşmeyi test etmek amacıyla, 7 test belirlemiştir. Testlerin tamamında yer alan istatistikler, "eşbütünleşme yoktur" sıfır hipotezine sahiptir. Pedroni (1999) eşbütünleşme testi, yatay kesit bağımlılığı olmadığı varsayımı altında 7 farklı test ile panel verilerinin eşbütünleşik olup olmadığının sınanmasında kullanılır. Bu 7 farklı testin 4 tanesi gruplar içi tahmincisini 3 tanesi ise gruplar arası tahmincisini kullanarak tahminlemede bulunur. Pedroni testini uygulamak için aşağıdaki model tahmin edilecektir.

$$
\text { endeks } s_{i t}=\alpha_{i}+\beta_{i} \text { havadurumu }_{i t}+\varepsilon_{i t}
$$

Modelde $t=1 \ldots T$ zaman periyodunu, $i=1 \ldots N$ panel ülkelerini göstermektedir. Çalışmada kullanılacak diğer eşbütünleşme testi ise Kao eşbütünleşme testidir. Kao (1999) tarafndan geliştirilen eşbütünleşme testi, DF (Dickey Fuller) ve ADF (Genelleştirilmiş Dickey Fuller) testlerini temel almaktadır. ADF test istatistiğinin anlamlı olması durumunda $H_{0}$ hipotezi reddedilmekte ve değişkenler arasında eşbütünleşme ilişkisi olduğu sonucuna varılmaktadır (Baltagi, ve diğ., 2000: 13).

Tablo 4. Panel Eşbütünleşme Test Sonuçları

\begin{tabular}{|c|c|c|c|c|}
\hline \multicolumn{5}{|c|}{ Pedroni Panel Eşbütünleşme Testi Sonucu } \\
\hline \multicolumn{5}{|l|}{ (Within-Dimension) } \\
\hline & t-istatistiğ $i$ & Olasillk & $\begin{array}{c}\text { Ăgırlıklandırılmus } \\
\text { t-istatistiği }\end{array}$ & Olasilık \\
\hline Panel v-Statistic & 0,0610182 & 0,2709 & $-0,611671$ & 0,7296 \\
\hline Panel rho-Statistic & 0,374355 & 0,6459 & 1,718206 & 0,9571 \\
\hline Panel PP-Statistic & 0,418049 & 0,662 & 2,358678 & 0,9908 \\
\hline Panel ADF-Statistic & 0,377857 & 0,6472 & 2,106728 & 0,9824 \\
\hline \multicolumn{5}{|l|}{ (between-dimension) } \\
\hline & $t$-istatistiğ $i$ & Olasilık & & \\
\hline Grouprho-Statistic & 1,48398 & 0,9311 & & \\
\hline Group PP-Statistic & 2,265316 & 0,9883 & & \\
\hline Group ADF-Statistic & 1,971906 & 0,9757 & & \\
\hline \multicolumn{5}{|c|}{ Kao Panel Eşbütünleşme Testi Sonucu } \\
\hline & \multicolumn{2}{|c|}{ t-istatistiği } & \multicolumn{2}{|c|}{ Olasilik } \\
\hline$A D F$ & \multicolumn{2}{|c|}{$-0,858053$} & \multicolumn{2}{|c|}{0,1954} \\
\hline Residualvariance & \multicolumn{2}{|c|}{212097,7} & & \\
\hline HAC variance & \multicolumn{2}{|c|}{205218,5} & & \\
\hline
\end{tabular}


Pedroni Eşbütünleşme test sonuçlarına göre hipotezi (seriler arasında eşbütünleşme yoktur) kabul edilmiştir. Test sonuçlarının tamamına ait istatistik değerleri $\% 5$ seviyesinde istatistiksel olarak anlamıdır ve eşbütünleşmenin olmadığını göstermektedir. Genel olarak değerlendirildiğinde bu yedi test sonucuna göre Pedroni Eşbütünleşme testi sonuçlarının seriler arasında uzun dönemli bir ilişki olmadığını söylemek mümkündür. Kao eşbütünleşme testine göre de hipotezi (seriler arasında eşbütünleşme yoktur) olasilık değerinin 0.05 'ten büyük olması nedeniyle kabul edilmiştir. Dolayısıyla Kao Eşbütünleşme test sonucuna göre de uzun dönemde ülke borsa endeksleri ile hava durumu arasında birlikte hareketin söz konusu olmadığ 1 sonucuna ulaşılmaktadır.

Tablo 5. Johansen Eşbütünleşme Test Sonuçları

\begin{tabular}{|c|c|c|c|c|}
\hline Hipotezler & $\dot{I z}$ Test Ist. & Olasillk & Max.Olabilirlik & Olasillk \\
\hline 0 & 27.22 & 0.0072 & 24.85 & 0.0155 \\
\hline 1 & 15.16 & 0.2331 & 15.16 & 0.2331 \\
\hline \multicolumn{5}{|c|}{ Bireysel Sonuçlar } \\
\hline Yatay Kesit & $\dot{I z}$ Test Ist. & Olasilık & Max.Olabilirlik & Olasilık \\
\hline \multicolumn{5}{|c|}{$H_{0}$ Hipotezi: Eşbütünleşme yoktur } \\
\hline$T R$ & 14.4574 & 0.2591 & 11.0325 & 0.2494 \\
\hline$I T$ & 18.4489 & 0.0871 & 10.8782 & 0.2610 \\
\hline$R U$ & 20.0597 & 0.0533 & 18.6455 & 0.0180 \\
\hline$A B D$ & 15.7794 & 0.1850 & 12.1176 & 0.1792 \\
\hline$C A$ & 18.5669 & 0.0841 & 15.7144 & 0.0533 \\
\hline$C N$ & 19.3845 & 0.0657 & 9.7446 & 0.3582 \\
\hline \multicolumn{5}{|c|}{$H_{1}$ Hipotezi: En az 1 Eşbütünleşme vardır } \\
\hline$T R$ & 3.4248 & 0.5045 & 3.4248 & 0.5045 \\
\hline$I T$ & 7.5706 & 0.0994 & 7.5706 & 0.0994 \\
\hline$R U$ & 1.4142 & 0.8885 & 1.4142 & 0.8885 \\
\hline$A B D$ & 3.6617 & 0.4648 & 3.6617 & 0.4648 \\
\hline$C A$ & 2.8526 & 0.6086 & 2.8526 & 0.6086 \\
\hline$C N$ & 9.6399 & 0.0406 & 9.6399 & 0.0406 \\
\hline
\end{tabular}

Tablo 5'te yer alan Johansen Eşbütünleşme test sonucuna bakıldığında, 'eşbütünleşme yoktur' sıfır hipotezi'ne ait olasılık değeri 0,05'ten küçük olduğundan hipotezi reddedilmektedir. En az 1 eşbütünleşme denklemi olduğunu ifade eden 2. Hipoteze ait olasılık değeri ise kabul edilmektedir. Ülkelere ait bireysel eşbütünleşme sonuçları tablonun devamında verilmiştir. Sonuçlara bakıldığında eşbütünleşme ilişkine sahip ülkelerin, Kanada ve Rusya olduğu görülmektedir. 


\subsection{Hata Giderme Modeli}

Seriler arasında uzun dönemli bir ilişkinin varlığ ispatlandıktan sonra, uzun dönemde ilişkili olan değişkenlerin kısa dönemdeki hareketlerinin gösterilmesi gerekmektedir. VAR modelinin kısa dönem analizi, vektör hata düzeltme mekanizması ile yapılmaktadır. Değişkenler arasında eş bütünleşme ilişkisi ortaya konulduktan sonra hava durumunun borsa endeksleri üzerindeki etkileri analiz etmek amaciyla hata düzeltme modeli (VECM) ile tahmin edilmiştir. Panel hata düzeltme modeline ait sonuç Tablo 6' da yer almaktadır.

Tablo 6. Hata Giderme Model Sonucu

\begin{tabular}{|cc|}
\hline Bağımlı Değ. & Bağımsız Değ \\
\hline index & hava durumu \\
1.000000 & 0.000307 \\
& $(1.108490)$ \\
& {$[0.2677]^{* *}$} \\
\hline
\end{tabular}

*AIC kriterlerine göre 8 gecikmeli model kullanılmıştır.

**Olasılık değeri

Hata giderme katsayısına ait olasılık değerinin 0.05 'ten büyük olmas1 nedeniyle, değişkenler arasındaki uzun dönem ilişki bulunmadığı söylenebilir. Değişkenlerin uzun dönem denge ilişkisi bulunmaması sebebiyle Wald testi uygulanarak, değişkenlerde kısa dönem ilişkisi bulunup bulunmadığı test edilmiştir.

\subsection{Wald Testi}

Kısa süreli nedensellik ilişkisini Wald testi kullanılarak analiz etmek mümkündür. Wald testi, kısıtsız regresyona dayalı bir test istatistiği hesaplar. Wald istatistiği, sıfır hipotezi altındaki kısıtlamaları karşılamak için kısıtsız tahminlerin ne kadar yakın olduğunu ölçer. Eğer kısıtlamalar doğruysa, bu durumda kısıtsız tahminler kısıtlamaları karşılamak için yaklaşmalıdır (Banumathy ve Azhagaiah, 2014:250). Wald testi ile hata giderme modelinde yer alan, bağımlı değişkenin açılayıcı değişken olarak yer aldığı 8 gecikmeli değerinin sıfıra eşitliği test edilmiştir. Tablo 7'de Wald testine ait sonuçlar yer almaktadir. 
Tablo 7. Wald Testi Sonucu

\begin{tabular}{|l|c|c|c|}
\hline Test istatistiği & Değer & $d f$ & Olasılık \\
\hline Ki-kare & 70.49509 & 7 & 0.0000 \\
\hline
\end{tabular}

Wald test sonucuna bakıldığında olasılık değerinin 0.05 'ten küçük olduğu görülmektedir. Borsa endeksi ile hava durumu arasında kısa dönem denge ilişkisi olduğunu söylemek mümkündür.

\section{Sonuç}

Çalışmada seçilen 6 ülke (Türkiye, İtalya, Amerika Birleşik Devletleri, Kanada, Çin Rusya) verisi kullanılarak hava durumu ile ülke borsa endeksleri arasındaki kısa ve uzun dönem denge ilişkisi incelenmiştir. Serilerde negatif değerler bulunması sebebiyle, orijinal serilerle çalışılmış, logaritma alınmamıştır. Öncelikle serilerin düzey değerlerinin durağanlığının araştırılması amacıyla panel birim kök testleri uygulanmış ve testlerde çelişkili sonuçlar elde edilmiştir. Bu nedenle serilerin ilk farkları alınmış ve birinci mertebeden durağan oldukları görülmüştür. Ülke borsa endeksleri () ve hava durumu değişkenleri I(1) seviyesinde durağan oldukları için ikinci aşama olan eşbütünleşme testine geçilmiştir.

Seriler arasındaki uzun dönemli ilişkinin sınanması amacıyla Pedroni, Kao ve Fisher Johansen panel eş bütünleşme testleri uygulanmış, Pedroni ve Kao test sonuçlarına göre ülke borsa endeksleri ile hava durumu arasında uzun dönemde eşbütünleşme ilişkisi olmadığı sonucuna ulaşılmıştır. Fisher Johansen panel eş bütünleşme sonuçlarına göre, ülke borsa endeksleri ile hava durumu arasında uzun dönem ilişki olmadığı sonucuna ulaşılmıştır. Yine Fisher Johansen analizinin verdiği bireysel eş bütünleşme sonuçlarında, Rusya ve Kanada için uzun dönem denge ilişkisinin olduğu görülmüştür. Kullanılan testlerle kesin bir sonuca ulaşılamamış olması nedeniyle Panel Hata Giderme Modeli (VECM) tahmin edilerek, uzun dönem denge ilişkisi tekrar test edilmiştir. VECM modelinde de değişkenler arasında uzun dönem denge ilişkisi bulunmadığı sonucuna ulaşı1mıştır. Borsa endeksinin hava durumu ile arasında kısa dönemli bir ilişkiye sahip olabileceği düşünüldüğünden, kısa dönem ilişkisi Wald testi ile sınanmıştır. Wald testi sonucuna göre ise, hava durumunun bağımlı değişken olan borsa endeksi üzerinde kısa dönemde bir etkiye sahip olduğu sonucuna ulaşılmıştır. Dolayısı ile seçilen ülkelerin temel borsa endeksleri ile hava durumu arasında kısa dönemde bir ilişki olduğunu ve birlikte hareket ettiğini ancak bu etkinin uzun vadeli devam etmediğini söylemek mümkündür. 


\section{Kaynakça}

Baltagi, Badi ve Kao, Chihwa 2000. "Nonstationary Panels, Cointegration in Panels and Dynamic Panels: A Survey”, Center for Policy Research Working Paper No:16.

Banumathy, Karunanithy ve Azhagaiah, Ramachandran .2014. Long-Run and Short-Run Causality between Stock Price and Gold Price: Evidence of VECM Analysis from India, Management Studies and Economic Systems (MSES), 1 (4), 247-256, Spring 2015.

Breitung, Jörg ve Pesaran, M. Hashem. 2008. Unit Roots and Cointegration in Panels. in The Econometrics of Panel Data, Springer, Heidelberg. Berlin, Germany.

Cao, M., \& Wei, J. (2005). Stock market returns: A note on temperature anomaly. Journal of Banking \& Finance, 29(6), 1559-1573.

Chang, T., Nieh, C. C., Yang, M. J., \& Yang, T. Y. (2006). Are stock market returns related to the weather effects? Empirical evidence from Taiwan. Physica A: Statistical Mechanics and its Applications, 364, 343-354.

Choi, In. 2001. "Unit Root Tests for Panel Data," Journal of International Money and Finance, 20: $249-272$.

Im, Kyung So, Pesaran, M. Hashem ve Shin, Yongcheol. 2003. "Testing for Unit Roots in Heterogeneous Panels," Journal of Econometrics, 115, pp. 53-74.

Cullen, M. M. (2003). Are Stock Prices Related to New York's Climatic Conditions?. Honors Theses. Paper 2119.

Dowling, M., \& Lucey, B. M. (2005). Weather, biorhythms, beliefs and stock returns-some preliminary Irish evidence. International Review of Financial Analysis, 14(3), 337-355.

Goetzmann, W. N., \& Zhu, N. (2005). Rain or shine: where is the weather effect?. European Financial Management, 11(5), 559-578.

Gunasekara, A. L., \& Jayasinghe, J. A. D. K. (2019). Does Weather Contribute to Stock Price Variation? A Cointegration Analysis. Kelaniya Journal of Management, C: 08, Say1:02

Hirshleifer, D., \& Shumway, T. (2003). Good day sunshine: Stock returns and the weather. The Journal of Finance, 58(3), 1009-1032.

Kamstra, M. J., Kramer, L. A., \& Levi, M. D. (2003). Winter blues: A SAD stock market cycle. American Economic Review, 93(1), 324-343.

Kang, S. H., Jiang, Z., \& Yoon, S. M. (2009). Weather effects on the returns and volatility of Hong Kong and Shenzhen stock markets. Korea Research Foundation.

Kao, Chihwa. 1999. "Spurious Regression and Residual-Based Tests for Cointegration in Panel Data", Journal of Econometrics, Volime:90, Issue:1, p.1-44.

Kim, J. H. (2017). Stock Returns and Investors' Mood: Good Day Sunshine or Spurious Correlation?. International Review of Financial Analysis, 52, 94-103.

Levin, Andrew, Lin, Chien-Fu ve Chu, Chia-Shang J. 2002. "Unit Root Test in Panel Data: Asymptotic and Finite Sample Properties", Journal of Econometrics 108, 1-24.

Loughran, T., \& Schultz, P. (2004). Weather, stock returns, and the impact of localized trading behavior. Journal of Financial and Quantitative Analysis, 343-364.

Pardo, A., \& Valor, E. (2003). Spanish stock returns: where is the weather effect?. European Financial Management, 9(1), 117-126. 
Pedroni, Peter. 1999. "Critical Values for Cointegration Tests in Heterogeneous Panels with Multiple Regressors”, Oxford Bulletin of Economics and Statistics, Special Issue, 662.

Pedroni, Peter. 2000. "Fully-Modified OLS for Heterogeneous Cointegrated Panels", Advances in Econometrics, 15, s.93-130.

Pedroni, Peter. 2001. "Purchasingpowerparitytests in cointegratedpanels", Review of Economics and Statistics, 83, s.727-731.

Sariannidis, N., Giannarakis, G., \& Partalidou, X. (2016). The effect of weather on the European stock market. International Journal of Social Economics.

Saunders, E. M. (1993). Stock prices and Wall Street weather. The American Economic Review, 83(5), 1337-1345.

Symeonidis, L., Daskalakis, G., \& Markellos, R. N. (2010). Does the weather affect stock market volatility?. Finance Research Letters, 7(4), 214-223.

Trombley, M. A. (1997). Stock prices and Wall Street weather: Additional evidence. Quarterly Journal of Business and Economics, 11-21.

Tufan, E., \& Hamarat, B. (2004). Do cloudy days affect stock exchange returns: Evidence from Istanbul stock exchange. Journal of Naval Science and Engineering, 2(1), 117-126.

Zeren, F., \& Gumus, F. B. (2015). Testing Weather Effect Anomalies: Time Varying Evidence from Selected Stock Markets. International Journal of Economic Perspectives, 9(1).

Wang, Y. H., Shih, K. H., \& Jang, J. W. (2018). Relationship among weather effects, investors' moods and stock market risk: An analysis of bull and bear markets in Taiwan, Japan and Hong Kong. Panoeconomicus, 65(2), 239-253. 


\section{Ekler}

\section{Ek. 1. Veri Tanımları}

BIST100 Endeksi: Borsa İstanbul Pay Piyasası için temel endeks olarak kullanılmaktadır. Yıldız Pazar ve Ana Pazar'da işlem gören şirketlerle, Kolektif Yatırım Ürünleri ve Yapılandırılmış Ürünler Pazarı'nda işlem gören gayrimenkul yatırım ortaklıkları ve girişim sermayesi yatırım ortaklıkları arasından seçilen 100 paydan oluşmakta olup, BIST 30 ve BIST 50 endekslerine dahil payları da kapsar.

MOEX Russia: MOEX Rusya Endeksi (Aralık 2017'ye kadar MICEX Endeksi olarak bilinir), Moskova Menkul Kıymetler Borsası'nda işlem gören 10 ana ekonomi sektöründen en büyük ve en likit 50 Rus şirketinin performansını izleyen büyük bir borsa endeksidir.

FTSE MIB: 40 İtalyan hisse senedinin performansını ölçer ve İtalyan borsasının geniş sektör ağırlıklarını yansıtmayı amaçlar. Endeks, Borsa Italiana (BIt) ana hisse senedi piyasasında işlem gören hisse senetlerinden türetilmiştir.

Dow Jones Industrial Average: Dow30 olarak da bilinen DJIA, New York Menkul Kıymetler Borsası ve NASDAQ'da işlem gören 30 büyük, halka açık bluechip şirketini kapsayan bir borsa endeksidir.

S\&P_TSX: Yaklaşık 250 şirketin dahil olduğu Toronto Menkul Kıymetler Borsası'ndaki toplam piyasa kapitalizasyonunun yaklaşık \%70'ini temsil eden Kanada gösterge endeksidir.

Shanghai Composite: SSE Endeksi olarak da bilinen SSE Bileşik Endeksi, Şanghay Menkul Kıymetler Borsası'nda işlem gören tüm hisse senetlerini (A hisseleri ve B hisseleri) içeren bir borsa endeksidir. 